\title{
Fetal Uptake of Intraamniotic Digoxin in Sheep
}

\author{
KUNIHIRO HAMAMOTO, HARRIET S. IWAMOTO, CHRISTINE M. ROMAN, LESLIE Z. BENET, \\ AND ABRAHAM M. RUDOLPH \\ Cardiovascular Research Institute and the Departments of Pediatrics, Physiology, Pharmacy, and Obstetrics, \\ Gynecology and Reproductive Sciences, University of California, San Francisco, California 94143
}

\begin{abstract}
To explore the possibility that intraamniotic administration of digoxin is an effective treatment regimen for fetal tachyarrhythmia, we injected digoxin into the amniotic fluid cavity of pregnant sheep and examined the time course of digoxin distribution to the fetal and maternal plasma compartments. Animals were studied in two groups according to digoxin dosage: $0.7-1.8 \mathrm{nmol} / \mathrm{kg}$ fetal body wt in the high-dose group $(n=6)$ and $0.1-0.6 \mathrm{nmol} / \mathrm{kg}$ fetal body $w t$ in the low-dose group $(n=14)$. Within $1 \mathrm{~h}$, plasma digoxin concentrations in the high-dose and low-dose groups were $18.2 \pm 15.0 \mathrm{nmol} / \mathrm{L}$ and $2.7 \pm 0.8 \mathrm{nmol} / \mathrm{L}$, respectively (values are expressed as mean $\pm \mathrm{SD}$ ). At $6 \mathrm{~h}$ digoxin concentrations were $13.8 \pm 7.0$ and $3.1 \pm 0.9 \mathrm{nmol} /$ $\mathrm{L}$, and at $24 \mathrm{~h}$ they were $2.3 \mathrm{nmol} / \mathrm{L}(n=1)$ and $1.8 \pm 1.2$ nmol/L, respectively. Peak maternal digoxin levels were about one-tenth fetal values in the high-dose group and undetectable in the low-dose group. Fetal digoxin concentrations were significantly greater in the descending aorta than in the umbilical vein $(p<0.02)$. Fetal arterial blood pressure and heart rate were not significantly different from control at any time after digoxin administration. These results demonstrate that digoxin is rapidly taken up into the fetal circulation from the maternal amniotic cavity. The exact mechanism whereby this occurs is unknown, but transplacental transfer from the maternal circulation is not involved. Our findings suggest that intraamniotic administration of digoxin may be an alternative treatment for fetal tachyarrhythmias when direct administration of antiarrhythmic agents is ineffective or produces maternal toxicity. (Pediatr Res 27: 282-285, 1990)
\end{abstract}

Fetal tachyarrhythmia, especially supraventricular tachycardia, is a cause of congestive heart failure and fetal death associated with nonimmune hydrops fetalis. Digoxin administration to pregnant women has been successful in the treatment of fetal tachyarrhythmia (1-8). Previous studies have demonstrated that digoxin easily crosses the placenta in the human $(9,10)$ and sheep (11). However, high concentrations of digoxin are required in the mother because placental transfer is variable $(1-11)$. Because transplacental digoxin therapy is unreliable, direct administration of digoxin to the fetus has been attempted.

Recently, Gembruch et al. (12) and Weiner and Thompson (13) reported that injecting digoxin directly into the fetal peritoneum or muscle effectively converted fetal tachycardia to normal sinus rhythm after attempts at transplacental therapy failed. However, to treat fetal tachyarrhythmia effectively, repeated injections were required to maintain elevated fetal plasma digoxin concentrations. Thus, direct fetal digoxin administration

Received July 21, 1989; accepted November 10, 1989

Correspondence and reprint requests Harriet S. Iwamoto, Ph.D., Box 0544, HSE 1403, Cardiovascular Research Institute, University of California, San Francisco, CA 94143.

Supported in part by NIH Grant GM26691. is impractical to treat tachyarrhythmia both because multiple intrafetal injections are required and because fetal plasma digoxin concentrations are difficult to control. To determine whether intraamniotic administration of digoxin might effectively treat fetal tachyarrhythmia, we injected digoxin into the amniotic cavity of pregnant sheep and measured the distribution of digoxin from the amniotic cavity to the fetal and maternal plasma compartments.

\section{MATERIALS AND METHODS}

Animals and surgical preparation. Surgery was performed on 19 ewes with 20 fetuses (one twin pregnancy) at 119-127 d of gestation. Surgical techniques to implant catheters into the ewe and the fetus have been described in detail previously (14). Briefly, after spinal anesthesia was induced in the ewe with $4 \mathrm{~mL}$ of $1 \%$ tetracaine hydrochloride, polyvinyl catheters were inserted into a peripheral artery and vein. The ewes were given an i.v. infusion of $0.9 \%$ saline during the operative procedure. Ketamine was administered intravenously in doses of $100 \mathrm{mg}$ every $15-20$ min. Through a midline incision, the uterus was exposed and the fetal hindlimbs identified. Polyvinyl catheters were inserted into a peripheral artery and vein of each hindlimb and advanced to the descending aorta and inferior vena cava. In seven fetuses, an $8 \mathrm{~F}$ polyvinyl catheter was inserted suprapubically into the urinary bladder through a purse-string suture (15). A $3.5 \mathrm{~F}$ multiple side-hole catheter was introduced into a distal cotyledonary tributary of the umbilical vein and advanced proximally toward the fetal body in 12 animals. Two catheters were also inserted into the amniotic cavity, one near the cervix and the other in the uterine horn. All catheters were exteriorized at the ewe's flank where they were protected in a cloth pouch sewn to the ewe's skin. Potassium penicillin ( 1 million U) and gentamicin $(50 \mathrm{mg})$ were administered to the ewe and into the amniotic cavity on the day of surgery and every day postoperatively.

Experimental protocol. One to $3 \mathrm{~d}$ after surgery, we studied the distribution of digoxin in the maternal-fetal unit. Digoxin was diluted in $20 \mathrm{~mL}$ saline and injected into the amniotic catheter located near the cervix. Initially we injected digoxin at an estimated dose of $1 \mathrm{nmol} / \mathrm{kg}$ fetal body wt in six fetuses (high dose). This increased fetal plasma digoxin concentrations to values greater than $15 \mathrm{nmol} / \mathrm{L}$. In another group of 14 fetuses, we injected digoxin at an estimated dose of $0.3 \mathrm{nmol} / \mathrm{kg}$ fetal body wt (low dose). At the end of the study the fetuses were weighed. Actual amounts of digoxin administered were $1.2 \pm$ $0.7 \mathrm{nmol} / \mathrm{kg}$ (high dose; mean $\pm \mathrm{SD}$ ) and $0.3 \pm 0.10 \mathrm{nmol} / \mathrm{kg}$ (low dose).

Blood samples $(0.20 \mathrm{~mL})$ were collected from the fetal descending aorta and umbilical vein and from the maternal artery at 0 , $0.25,0.5,1.0,2.0,4.0,6.0,24,48$, and $72 \mathrm{~h}$ after injection of digoxin. Whenever possible, amniotic fluid samples from the two amniotic catheters and fetal urine samples were collected simultaneously. All blood samples were centrifuged immediately after collection, decanted, and stored at $4^{\circ} \mathrm{C}$ until they were assayed. Urine and amniotic fluid samples were also assayed. 
Digoxin concentration in each sample was measured by radioimmunoassay (Amerlix Digoxin RIA kit Amersham Co., Arlington Heights, IL); this assay does not detect digoxin-like immunoreactive substance (16). Fetal arterial blood gases, $\mathrm{pH}$, and hemoglobin were measured daily using a blood gas analyzer (158 $\mathrm{pH} /$ blood gas analyzer, Corning Medical, Medfield, MA) and a Hemoximeter (OSM2, Radiometer, Copenhagen, Denmark).

In 15 animals, fetal vascular pressures were measured with Statham P23Dc transducers (Statham Instruments, Santa Ana, $\mathrm{CA}$ ), and heart rate was recorded continuously with a Beckman cardiotachometer (Beckman Instruments Inc., Fullerton, CA) triggered by the arterial pulse wave and a Beckman type RM direct writing recorder. All pressures were corrected using amniotic pressure as a zero reference. Data were analyzed by paired $t$ test with correction for multiple comparisons. All values are expressed as mean $\pm \mathrm{SD}$.

\section{RESULTS}

In the fetuses at the beginning of the study, $\mathrm{pH}$ was $7.35 \pm$ $0.03, \mathrm{PCO}_{2}$ was $7.6 \pm 0.5 \mathrm{kPa}$, and $\mathrm{PO}_{2}$ was $2.4 \pm 0.5 \mathrm{kPa}$. Four hours after digoxin administration, $\mathrm{pH}, \mathrm{PCO}_{2}$, and $\mathrm{PO}_{2}$ were 7.33 $\pm 0.09,7.8 \pm 1.1 \mathrm{kPa}$, and $2.5 \pm 0.5 \mathrm{kPa}$, respectively. These values were not significantly different from control values.

Before digoxin administration, digoxin immunoreactivity could not be detected in fetal and maternal plasma or amniotic fluid, nor in fetal urine. Figure 1 depicts mean fetal digoxin concentrations in aortic plasma in both high- and low-dose groups. In the high-dose group, digoxin concentrations rose rapidly to $18.2 \pm 15.0 \mathrm{nmol} / \mathrm{L}$ at $1 \mathrm{~h}$ and were maintained for 6 h. Digoxin concentrations in the low-dose group also increased rapidly, reaching $2.7 \pm 0.8 \mathrm{nmol} / \mathrm{L}$ within $1 \mathrm{~h}$ and remaining elevated for at least $6 \mathrm{~h}$. There were no significant differences between values at 1,4 , and $6 \mathrm{~h}$ in either group.

As shown in Table 1, the average peak concentrations of digoxin in fetal plasma in the high- and low-dose groups were $20.0 \pm 10.9$ and $3.4 \pm 0.7 \mathrm{nmol} / \mathrm{L}$, respectively. The time to reach the peak concentration varied in each case, and had no correlation with fetal arterial $\mathrm{pH}, \mathrm{PO}_{2}$, or $\mathrm{PCO}_{2}$. There was also no statistically significant relationship between digoxin dose, peak digoxin concentration, or arterial blood gases. Peak digoxin concentrations in the ewe's plasma were about one-tenth of fetal concentrations in the high-dose group, but were below the assay detection limit in 10 of 11 ewes in the low-dose group. We also measured the digoxin concentration of amniotic fluid in 11

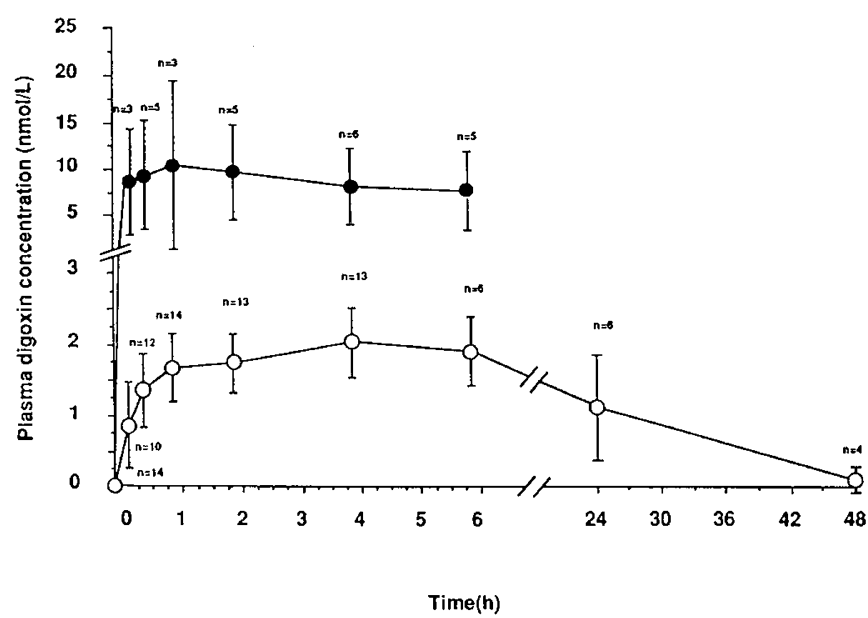

Fig. 1. Plasma digoxin concentrations in fetal sheep following intraamniotic injection. Digoxin concentrations in the descending aorta remained elevated for at least $6 \mathrm{~h}$ after a single injection in both the highdose (solid symbols) and low-dose (open symbols) groups. Data shown are mean $\pm \mathrm{SD}$ and $n$ values indicate the number of measurements available for each time point. animals and calculated the ratio of fetal arterial digoxin concentration to that of amniotic fluid. These ratios, expressed as percentages, ranged from 0.4 to $4.9 \%$ in the high-dose group and from 0.7 to $3.1 \%$ in the low-dose group.

Sampling was not complete in the high- or low-dose studies. However, sufficient fetal arterial samples were obtained at early time points to give some indication of dose linearity. Comparison of fetal arterial peak concentrations as presented in Table 1 show a 5.8 -fold increase $(20.0 \pm 10.9$ versus $3.4 \pm 0.7)$ in peak concentration with a 4-fold increase in dose. Comparison of areas under the curve of fetal arterial concentrations from 0 to 4 $\mathrm{h}$ and from 0 to $6 \mathrm{~h}$ (values not shown) yielded high to low dose ratios of 5.8 and 5.1, respectively. Considering the variability observed, it appears that a rough dose linearity does exist for digoxin injected into the amniotic fluid.

In 11 animals, we compared the digoxin concentration in plasma samples taken simultaneously from the fetal aorta and umbilical vein. At the time of peak values, fetal digoxin concentrations in aortic plasma $(21.4 \pm 11.6 \mathrm{nmol} / \mathrm{L})$ were slightly higher than those in umbilical venous plasma $(18.8 \pm 12.1 \mathrm{nmol} /$ $\mathrm{L}$ ) in the high-dose group, and significantly greater in the lowdose group (aorta: $3.6 \pm 0.8 \mathrm{nmol} / \mathrm{L}$, umbilical vein: $2.2 \pm 0.8$ $\mathrm{nmol} / \mathrm{L}, p<0.015)$. Figure 2 illustrates the time course of digoxin concentrations in a single animal. Linearity is demonstrated by the "fetal extraction ratio," calculated as one minus the ratio of umbilical venous to descending aortic concentrations. Such measurements were available $4 \mathrm{~h}$ after dosing in five fetuses that received the high dose and in six that received the low dose. The mean fetal extraction ratios were $0.10 \pm 0.17$ and $0.10 \pm 0.13$ for the high and low doses, respectively. In each group one fetus exhibited a negative extraction, i.e. venous concentrations exceeded aortic. If these values are omitted, the high- and low-dose extraction ratios average $0.16 \pm 0.11$ and $0.14 \pm 0.08$, respectively, suggesting similar digoxin elimination rates at both high and low doses.

We measured heart rate and blood pressure in the fetal aorta before and after injecting digoxin in both groups. Initially, heart rate and blood pressure in the high-dose group were $196 \pm 34$ / min and $5.8 \pm 0.4 \mathrm{kPa}$, respectively; in the low-dose group heart rate was $190 \pm 34 / \mathrm{min}$ and blood pressure was $6.2 \pm 0.7 \mathrm{kPa}$. Neither heart rate nor blood pressure changed significantly throughout the observation period.

\section{DISCUSSION}

Multiple reports (2-8) have been published since Lingman et al. (1) first described successful transplacental treatment to convert supraventricular tachycardia to sinus rhythm with digoxin. In almost all of these reports, digoxin was administered to mother. But placental transfer of digoxin is erratic, varying not only among the previous case reports $(1-5,7,8)$ but also among studies (9-11). In one case report (2), the concentration of digoxin in umbilical cord blood was about one-fourth the concentration in maternal blood; in another (3), digoxin concentration in umbilical cord blood was almost the same as that in maternal blood. Furthermore, in some cases $(4,8)$ the dose of digoxin had to be reduced to avert maternal toxicity. Direct fetal administration of digoxin has been reported recently $(12,13)$. Although this mode of therapy effectively converted tachycardia to normal sinus rhythm, fetal digoxin administration is impractical because it requires multiple intrafetal injections to maintain the digoxin concentration.

We showed that intraamniotic injection of digoxin increased fetal digoxin concentrations within the therapeutic range for a prolonged period of time. The digoxin concentration measurements suggest that digoxin was transferred directly from amniotic fluid to the fetal circulation as has been shown previously for thyroxine (17) and $\beta$-blocking agents (18). Maternal digoxin concentrations were always significantly lower than fetal meas- 
Table 1. Fetal gestational age, wt, and digoxin concentration measurements

\begin{tabular}{|c|c|c|c|c|c|c|c|c|}
\hline & \multirow[b]{2}{*}{$\begin{array}{c}\text { Gestational } \\
\text { age (d) }\end{array}$} & \multirow{2}{*}{$\begin{array}{c}\text { Fetal } \\
\text { wt } \\
(\mathrm{kg}) \\
\end{array}$} & \multirow{2}{*}{$\begin{array}{c}\text { Digoxin } \\
\text { dose } \\
(\mathrm{nmol} / \mathrm{kg})\end{array}$} & \multicolumn{5}{|c|}{ Peak digoxin concentration* } \\
\hline & & & & $\begin{array}{l}\text { Time } \\
(\mathrm{min})\end{array}$ & $\begin{array}{c}\text { FA } \\
(\mathrm{nmol} / \mathrm{L})\end{array}$ & $\begin{array}{c}\text { Fetal urine } \\
(\mathrm{nmol} / \mathrm{L})\end{array}$ & $\begin{array}{c}\mathrm{MA} \\
(\mathrm{nmol} / \mathrm{L})\end{array}$ & $\begin{array}{c}\mathrm{AF} \\
(\mathrm{nmol} / \mathrm{L})\end{array}$ \\
\hline \multicolumn{9}{|c|}{ High-dose group } \\
\hline 1 & 122 & 2.25 & 1.2 & 120 & 15.3 & NA & 4.6 & NA \\
\hline 2 & 123 & 2.15 & 1.8 & 240 & 22.3 & NA & 2.3 & 451 \\
\hline 3 & 121 & 3.05 & 1.3 & 15 & 34.6 & NA & 3.4 & 4352 \\
\hline 4 & 123 & 3.20 & 0.8 & 60 & 5.2 & NA & 1.4 & 1345 \\
\hline 5 & 122 & 1.60 & 1.6 & 240 & 13.5 & 71.7 & 0.6 & 679 \\
\hline 6 & 123 & 2.60 & 0.7 & 30 & 29.5 & 53.8 & 1.3 & 681 \\
\hline Mean & 122 & 2.48 & 1.2 & 118 & 20.0 & 62.8 & 2.3 & 1501 \\
\hline$\pm \mathrm{SD}$ & \pm 1 & \pm 0.60 & \pm 0.7 & \pm 101 & \pm 10.9 & & \pm 1.5 & \pm 1628 \\
\hline \multicolumn{9}{|c|}{ Low-dose group } \\
\hline 1 & 122 & 3.15 & 0.4 & 60 & 1.9 & NA & NA & $\mathrm{NA}$ \\
\hline 2 & 124 & 2.00 & 0.6 & 240 & 5.1 & NA & ND & 236 \\
\hline 3 & 123 & 2.35 & 0.3 & 360 & 3.6 & 0.7 & ND & $\mathrm{NA}$ \\
\hline 4 & 125 & 2.60 & 0.2 & 60 & 2.5 & 13.2 & ND & 371 \\
\hline 5 & 133 & 2.25 & 0.3 & 60 & 3.9 & NA & ND & 342 \\
\hline 6 & 123 & 1.25 & 0.5 & 240 & 3.5 & $\mathrm{NA}$ & ND & NA \\
\hline 7 & 123 & 2.65 & 0.2 & 60 & 3.6 & 17.9 & ND & NA \\
\hline 8 & 123 & 2.05 & 0.3 & 60 & 3.3 & NA & ND & 371 \\
\hline 9 & 119 & 2.00 & 0.3 & 30 & 3.4 & 2.9 & ND & NA \\
\hline 10 & 121 & 2.00 & 0.3 & 240 & 4.0 & NA & NA & NA \\
\hline 11 & 125 & 1.99 & 0.3 & 240 & 3.1 & NA & NA & NA \\
\hline 12 & 123 & 1.10 & 0.3 & 360 & 3.5 & NA & ND & 493 \\
\hline 13 & 123 & 2.23 & 0.1 & 30 & 3.9 & NA & ND & 128 \\
\hline 14 & 127 & 3.00 & 0.2 & 120 & 2.9 & NA & 0.7 & NA \\
\hline Mean & 124 & 2.19 & 0.3 & 154 & 3.4 & 8.7 & & 324 \\
\hline$\pm \mathrm{SD}$ & \pm 3 & \pm 0.57 & \pm 0.1 & \pm 121 & \pm 0.7 & \pm 8.2 & & \pm 127 \\
\hline
\end{tabular}

* Measured when highest fetal arterial value was detected. FA, fetal artery; MA, maternal artery; AF, amniotic fluid; ND, not detectable; NA, not available.

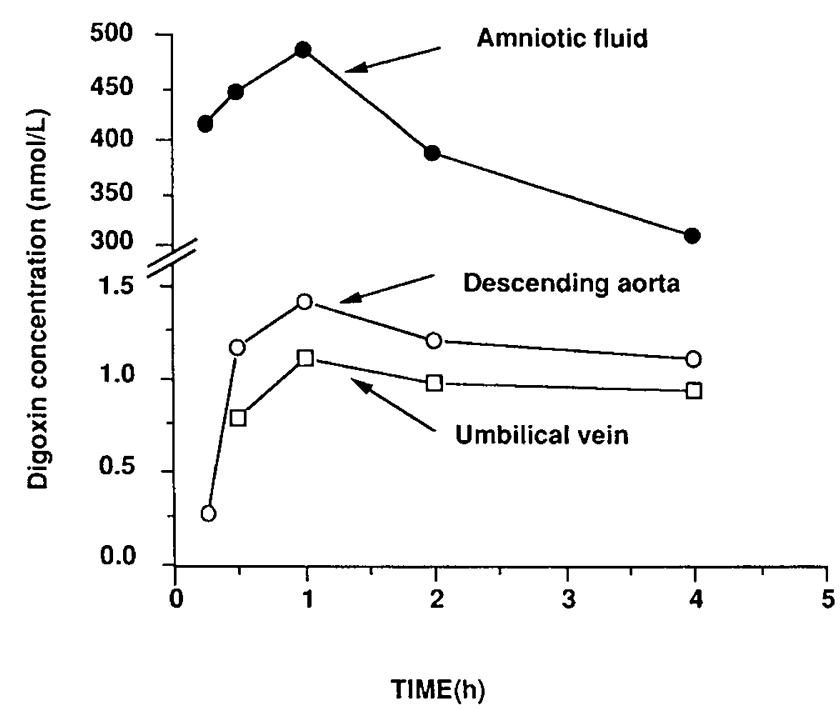

Fig. 2. Time-course of digoxin concentrations in fetal plasma and amniotic fluid. In a single animal (no. 4, low-dose group), this graph illustrates the relationship between concentrations of digoxin in amniotic fluid, the descending aorta, and the umbilical vein following intraamniotic injection of $0.24 \mathrm{nmol}$ digoxin $/ \mathrm{kg}$ fetal body wt. Note that at all time points, the digoxin concentration in the descending aorta was greater than in the umbilical vein and the concentration in amniotic fluid was about 150 times that in fetal plasma.

urements so transplacental transfer of digoxin likely proceeded in the fetal-to-maternal direction.

Singh et al. (11) and Berman et al. (19) investigated the elimination kinetics of digoxin administered i.v. in maternal and fetal sheep. Both reports showed that the fetal digoxin concentra- tion declined quickly after bolus injection or cessation of an infusion. In our study, fetal digoxin concentration decreased slowly after intraamniotic bolus injection in a manner consistent with slow absorption from another compartment. Absorption of digoxin by the fetus from amniotic fluid could occur by swallowing. However, fetal swallowing does not occur continuously, and intervals between swallowing have been reported to be as long as $2.31 \mathrm{~h}(20)$. Given the improbability that each fetus swallowed at the beginning of our study, swallowing is unlikely to be the only mechanism of digoxin absorption by the fetus from amniotic fluid. Furthermore, in one fetus, we ligated the esophagus to eliminate the possibility of swallowing and injected digoxin into the amniotic cavity. In this fetus, the digoxin concentration curve over time was similar to that of other fetuses and the peak concentration achieved was $3.6 \mathrm{nmol} / \mathrm{L}$. In a recent preliminary communication, Gilbert et al. (21) reported that fetal plasma concentrations of arginine vasopressin increased in esophagealligated fetuses after intraamniotic injection of arginine vasopressin. Skin is a possible route of digoxin absorption because arterial digoxin concentrations exceeded umbilical venous. However, fetal skin is covered with hair at this stage of gestation, making significant transdermal diffusion unlikely. One other possible pathway is the interface between the amniotic fluid and fetal vessels in the amniotic membrane or near the placenta. If significant uptake occurred near the placenta, we should have detected higher, rather than lower, concentrations of digoxin in the umbilical vein than in the descending aorta. Although the exact site of digoxin absorption into the fetal circulation is unknown, it is apparent that the site where venous drainage from this area returns to the fetus is downstream from the umbilical veins.

Amniotic fluid containing a high concentration of digoxin could act as a reservoir that sustains an adequate digoxin level in the fetus. Therefore, intraamniotic administration of digoxin should be considered as a possible treatment for fetal congestive 
heart failure associated with tachyarrhythmia when the condition either does not respond to maternally administered antiarrhythmic agents or cannot be treated because elevated drug concentrations would result in maternal toxicity. Because there are considerable species differences in placental and amniotic membrane anatomy and transport, it is most important to determine the pharmacokinetics of intraamniotically administered digoxin in the pregnant woman before clinical use can be recommended.

\section{REFERENCES}

1. Lingman G, Ohlander S, Ohlin P 1980 Intrauterine digoxin treatment of fetal paroxysmal tachycardia. Case report. Br J Obstet Gynaecol 87:340-342

2. Kerenyi TD, Gleicher N, Meller J, Brown E, Steinfeld L, Chitkara U, Raucher H 1980 Transplacental cardioversion of intrauterine supraventricular tachycardia with digitalis. Lancet 2:393-394

3. Harrigan JT, Kangos JJ, Sikka A, Spisso KR, Natarajan N, Rosenfeld D, Leiman S, Korn D 1981 Successful treatment of fetal congestive heart failure secondary to tachycardia. N Engl J Med 304:1527-1529

4. Heaton FC, Vaughan R 1982 Intrauterine supraventricular tachycardia: cardioversion with maternal digoxin. Obstet Gynecol 60:749-752

5. King CR, Mattioli L, Goertz KK, Snodgrass W 1984 Successful treatment of fetal supraventricular tachycardia with maternal digoxin therapy. Chest 85:573-575

6. Abramowicz J, Jaffe R, Altaras M, Ben-Aderet N 1985 Fetal supraventricular tachycardia: prenatal diagnosis and pharmacological reversal of associated hydrops fetalis. Gynecol Obstet Invest 20:109-112

7. Golichowski AM, Caldwell R, Hartsough A, Peleg D 1985 Pharmacologic cardioversion of intrauterine supraventricular tachycardia. A case report. $J$ Reprod Med 30:139-144

8. Nagashima M, Asai T, Suzuki C, Matsushima M, Ogawa A 1986 Intrauterine supraventricular tachyarrhythmias and transplacental digitalization. Arch Dis Child 61:996-1000

9. Rogers MC, Willerson JT, Goldblatt A, Smith TW 1972 Serum digoxin concentrations in the human fetus, neonate and infant. $\mathrm{N}$ Engl $\mathrm{J}$ Med 16:1010-1013

10. Chan V, Tse TF, Wong V 1978 Transfer of digoxin across the placenta and into breast milk. Br J Obstet Gynaecol 85:605-609

11. Singh H, Fehr PE, Mirkin BL 1978 Elimination kinetics and placental transfer of digoxin in pregnant and nonpregnant ewes. Res Commun Chem Pathol Pharmacol 20:31-42

12. Gembruch U, Hansmann M, Redel DA, Bald R 1988 Intrauterine therapy of fetal tachyarrhythmias: intraperitoneal administration of antiarrhythmic drugs to the fetus in fetal tachyarrhythmias with severe hydrops fetalis. $\mathbf{J}$ Perinatol Med 16:39-44

13. Weiner CP, Thompson MI 1988 Direct treatment of fetal supraventricular tachycadia after failed transplacental therapy. Am J Obstet Gynecol 158:570573

14. Rudolph AM, Heymann MA 1980 Methods for studying the circulation of the fetus in utero. In: Nathanielsz PW (ed) Animal Models in Fetal Medicine. Elsevier, North-Holland Biomedical Press, Amsterdam, pp 1-57

15. Iwamoto HS, Rudolph AM 1983 Chronic renal venous catheterization in fetal sheep Am J Physiol 245:H524-H527

16. Greenway DC, Nanji AA 1985 Falsely increased results for digoxin in sera from patients with liver disease: ten immunoassay kits compared. Clin Chem 31:1078-1079

17. Van Petten GR, Mears MJ, Mathison JH 1978 Transfer of beta-blocking drugs from the amniotic fluid to the fetal and maternal circulation. J Pharmacol Exp Ther 207:641-649

18. Klein AH, Hobel CJ, Sack J, Fisher DA 1978 Effect of intraamniotic fluid thyroxine injection on fetal serum and amniotic fluid iodothyronine concentrations. J Clin Endocrinol Metab 47:1034-1037

19. Berman Jr W, Ravenscroft PJ, Sheiner LB, Heymann MA, Melmon KL, Rudolph AM 1977 Differential effects of digoxin at comparable concentrations in tissues of fetal and adult sheep. Circ Res 41:635-642

20. Harding R, Sigger JN, Poore ER, Johnson P 1984 Ingestion in fetal sheep and its relation to sleep states and breathing movements. Q J Exp Physiol 69:477486

21. Gilbert WM, Cheung CY, Brace RA 1989 A new intramembranous/intraplacental pathway for absorption from amniotic fluid into the fetal circulation. Abstracts for the 36th Annual Meeting of the Society for Gynecologic Investigation, San Diego, CA p 226(abstr) 